\title{
Preconditions FOR SETTING UP E-TRAINING FOR SME TEXTILE COMPANIES IN SERBIA
}

\author{
PARDANJAC, M.; JOKIC, S.; STANISAVLJEV, S.; \\ ZUBANOV, V.; TASIC, I. \& MILANOV, D.
}

Abstract: Market demands towards the textile industry are constantly evolving causing the need for constant adaptation to new technologies and its processes. Therefore the employees need to continuously improve through additional training, particularly in SME (small and medium enterprises) companies which require flexible manufacturing. This manuscript analyzed the e-training as one of possible ways of training. As the majority of employees in the textile industry are low-qualified manual workers, at an average of $90 \%$, implementing an E-training can be a challenge. Training like this is affected by several prerequisite factors. This manuscript monitored the influence of the computer literacy, motivation, age structure and educational level of employees. Research was conducted on a representative sample of the SME textile industry companies in Serbia. The results are analyzed and presented by descriptive analysis and Person's correlation coefficient, and indicate measures that need to be taken to make the company training successful and increase productivity and efficiency in the small and medium textile industry businesses in Serbia.

Key words: e-training, textile industry, small and medium companies, competitiveness
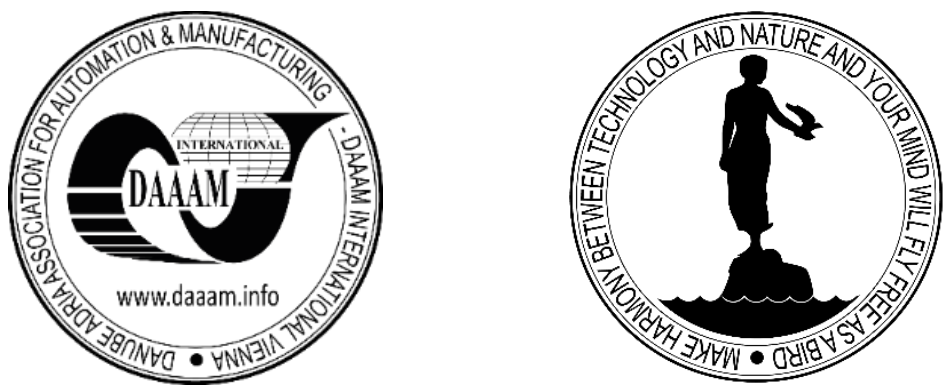

Authors' data: Pardanjac, M[arjana]*; Jokic, S[nezana]**; Stanisavljev, S[anja]*; Zubanov, V[ioleta]***, Tasic, I[van]*, Milanov, D[usanka]*, *University of Novi Sad, Technical Faculty „Mihajlo Pupin“, Djure Djakovica bb, Zrenjanin, Serbia, **International University of Novi Pazar, Dimitrija Tucovica bb, Novi Pazar, Serbia, ***Faculty for sport and tourism, Radnička 30a, Novi Sad, Serbia, marjana.pardanjac@tfzr.rs,_snezana.jokic@yahoo.com,_sanja@ttzr.uns.ac.rs, violeta.zubanov@tims.edu.rs, epsodzaci@gmail.com,dusanka.milanov@gmail.com

This Publication has to be referred as: Pardanjac, M[arjana]; Jokic, S[nezana]; Stanisavljev, S[anja]; Zubanov, V[ioleta]; Tasic, I[van] \& Milanov, D[usanka] (2017). Preconditions for Setting up E-training for SME Textile Companies in Serbia, Chapter 03 in DAAAM International Scientific Book 2017, pp.029-042, B. Katalinic (Ed.), Published by DAAAM International, ISBN 978-3-902734-12-9, ISSN 1726-9687, Vienna, Austria

DOI: $10.2507 /$ daaam.scibook.2017.03 
Pardanjac, M.; Jokic, S.; Stanisavljev, S.; Zubanov, V.; Tasic, I. \& Milanov, D.: Pre...

\section{Introduction}

Today, employees are expected to receive process and learn more information than ever before. New findings are developing continuously; therefore, acquired knowledge should be renewed and supplemented with new, because it becomes obsolete. Changes related to production, market or technology strategies and processes of businesses in the textile industry are frequent and demand for appropriate changes in training of the employees. At present time, knowledge of employees is not traditionally limited with time and space; it is believed that as long as work is done, it does not matter where and how it was done. Modern training methods should reflect the changes in lifestyle. Permanent development of human resources is simply enforced on small and medium companies (further SME). Their ability to educate and train their employees during work time is of great value. If present SME's want to provide training for their employees, solutions to following questions are needed: What is the appropriate solution that will enable their employees to keep up with rapid changes in the corporate textile world? Can e-training be a solution to that? Do computer literacy and age structure affect the effectiveness of e-training?

Textile industry is an important industrial branch since it produces clothing for 7 billion people as well as textile materials for technical applications. It is internationally integrated, it falls into traditional branches of manufacturing industries and employs great number of low waged and low qualified, mostly female, workforce. It is very demanding both in technical and technological means. To respond to those demands, continuous education of the workforce is necessary. Workers need to be competitive, educated and skilled to respond adequately to all challenges and requirements of big fluctuations and fast changes at the market (Jovanović, 2005).

Textile industry in Serbia covers production, trade and other service activities. Production activity covers processing of raw fibber materials and the production of fabrics, yarn and knitted products. The basic raw materials used are: wool, linen, cotton, silk, jute, etc. The major products of textile industry in Serbia are: clothing (dresses, skirts, shirts, scarves, sweaters, socks, underwear, pajamas, nightgowns, etc.), accessories (bags, purses, wallets, belts, jackets, hats and other leather accessories), knitwear and yarns. Textile industry is a specific branch of industry in terms of the specific seasonal character. Its capacities are used during whole time of year, but in tune with the season. In that way, the influence of the season is of great importance in sale of the textile industry products, resulting in unbalanced contribution to sales and income of different product lines and products.

\section{Literature Review}

Market globalization, new informational and communication technologies accelerate trading trends, customer demands become more complex and personal. "New products and services are emerging with accelerating speed"(Bachman, 2010). New challenges force SME to adapt quickly to new client demands. While at the same time the production cycle and the life cycle of the products continue to decrease, information and training out-date in a fast pace (Mulc, Udiljak \& Ciglar, 2015). 
Development of intellectual equity became the key factor to earning and sustaining competitive advantage on the market. It is important to know what, how and why something needs to be done.

New challenges that impose on businesses, and therefore employees, are triggering the need for learning and training. Lack of qualified workforce, the larger flexibility of employees at work, the globalization of operations, etc. are some of the challenges that occur. On the other hand, managers are responsible for providing the knowledge and skills, faster and more efficient whenever and wherever needed. In an era of just-in-time production, only just in-time training becomes the key element of management success. Managers realized that if company offers education and training for their employees that is up-to-date, they would have greater rate of performance as well as better-qualified workforce (Derouin, Fritzsche \& Salas, 2005). Possibility of training is important for attracting new employees. Increasing capabilities of the existing workforce "in house" definitely affects the increase of employee satisfaction, increases productivity, profitability and competence on the textile market.

The training involves changes in specific knowledge, abilities, skills, attitudes or behavior of employees in order to prepare them for a better performance at the current job (Tynjala \& Hakkinen, 2010). It may be useful for adoption of new technologies, increasing knowledge about foreign markets, quality of teamwork, innovation, job ensuring, mutual acceptance and successful cooperation.

\subsection{E-training}

In this paper E-training implies to learning based on informationalcommunicative technologies, namely for delivering content of training trough all electronic media, including internet, intranet and extranet. Training of employees in SME through e-training became the most frequent way of training in today's world since it provides training of employees from different departments from different locations throughout the country. Managers in the textile SME use E-training to introduce their employees to technological processes, to shorten time needed for staff training for new procedures or products, to connect with their procuring and distributing chains, to distribute the work-load and to decries differences in the training between different company parts. With technology evolving at the current pace, the borders of e-learning are practically unlimited. For young people, who live and progress in the digital environment, technology is a natural part of learning, problem solving, connecting and support in training. "Workers can also improve productivity and use their own time more efficiently, as they no longer need to travel or fight rushhour traffic to get to a class" (Bachman, 2010). "Training courses could also be provided immediately almost on an a la carte basis, rather than waiting until the required number of participants has been gathered for a conventional, face-to-face, offsite course" (Hamburg, 2005).

Like any educational technology, E-training also has its cons. The major con is a demand for an employee to have access to a computer as well as the Internet. They also need to have certain computer skills. Technical issues as slow internet connection or slow access to the materials due to server overload can cause frustration and withdrawals from the training. Due to decreased social interaction, employees may feel 
Pardanjac, M.; Jokic, S.; Stanisavljev, S.; Zubanov, V.; Tasic, I. \& Milanov, D.: Pre...

isolated from their instructors. Instructions are not always available; therefore trainees should have the discipline for work independently, without the help of an instructor. E-trainees also need to have good computer skills (Jokic, Pardanjac \& Bradonjic, 2010).

\subsection{Factors Affecting Employees E-Training}

There are many factors that can influence the outcome of E-training. Factors that were analyzed in this paper were: age structure, acquired education level, motivation for this kind of training as well as possession of computer literacy.

\subsubsection{Age structure}

The age structure is one of the factors that are often mentioned and used in analyzing the structure of employees. This criterion is very important as it has a significant impact on labor productivity. Aging refers to all possible changes that occur in the biological, psychological and even social functioning at various points in the life cycle.

Many studies explore how the relationship between age and age stereotypes (Van der Heijden, 2006; Van der Heijden, De Lange, Demerouti \& Van der Heijde, 2009); or performance at workplace $(\mathrm{Ng} \&$ Feldman, 2008); or relationship between colleagues and situations at work (Ng \& Feldman, 2013; Wang, Zhan, Liu \& Shultz, 2008 ) influence the decisions of the elderly workers to accept additional e-training. All these papers show the different approaches that can be used to understand the complex effects of additional training on adults and their behavior at the workplace.

Employees, near to retirement age are less interested in the work and labor performances than younger employees, which are in upswing of theirs work activity. This raises the question of whether age structure may affect the interest of workers for education through E-training.

\subsubsection{Educational structure}

Employees in the textile industry are mostly low qualified, with elementary or high school degree. Therefore, they are persons who were not much interested for prior education, so a question is asked whether they will have enough interest for further education. Often they do not see the advantages of the training, so it takes a lot more input of energy and motivation in the process of getting them to understand the necessity of additional training and education. Unlike them, it is assumed that the employees with higher level of education will rather accept new trainings, since they consider that in such way they will have stronger chances for further development and employment, which directly affects the implementation of E-training. Many authors (Evans and Fan, 2002; McNaughton, 2001; Raymond, 2000), considered that e-training is providing the opportunity of access to further education. Benefits of additional training are not only important for the individual, but also for the company in which the employee works (Blundell, Dearden, Meghir \& Sianesi, 1999; Kennedy, 1997; Tight, 2002). 


\subsubsection{Motivation}

Motivation can be defined as a process of triggering, directing and maintaining one's behavior towards a certain goal. There are three processes forming the basis of motivation: need, motion and reward. Need is the state of either physiological or psychological misbalance. Motion is the action undertaken by a man in order to eliminate this misbalance, while removal of this misbalance or neutralizing of tension is, in fact, the reward.

Furthermore, three dimensions of motivation are important for understanding its influence on employees work capabilities: direction, intensity and constancy. In order for an employ to be properly motivated, his motivation has to have certain direction. Secondly, motivation intensity is in fact the amount of effort that one should use, in a time unit, to fulfill his needs. Finally, motivation constancy represents the time of making a certain level of effort in a certain direction.

There are numerous motivation theories (Fisher, 2009), which try to explain what motivates people to work, as well as the way the motivation process is taking place. These theories can be split into two groups: content theories and process theories. Content theories (Roberts, Treasure \& Conroy, 2007) try to give the answers to the question what triggers human activity, while process theories try to identify a process, which motivates people for undertaking certain activities, i.e. how the human behavior is triggered.

The behavior of employees divides into needed behavior for achieving company goals and behavior for the rewards. Biggest task of management is to secure that those two behaviors are connected. One of the ways for that is introducing motivational stimulations into the companies (introducing new and more complex tasks, giving freedom to employees to develop their own concrete tasks, allowing possibilities for additional training and specialization). That training can be organized through Etraining. The fact that majority of employees in the textile industry are low qualified, implies that they will need additional motivation for the E-training.

The possibility that training can take place at anytime and anywhere, based on the employee preference, increases the rate of their motivation for that type of training and represents one of the most important advantages of e-training.

\subsubsection{Computer literacy}

Along with the elementary - primary literacy (e.g. knowing to read and write as basic skills), today we speak also about term of secondary - functional literacy (e.g. using certain products, filing contracts and forms, trading orientation, turnover, public institutions, etc.) as well as tertiary literacy (IT, computer, internet, SMS). The majority of people do not participate in the last two groups of literacy or communication.

Computer literacy is defined as the knowledge and ability for effective use of the computers and technology in general. It also refers to the degree of skill that one has for using computer programs and other applications that are connected to a computer. Computer integration has many faces and forms: from internet, mobile phone, computer integrated manufacturing, e-technologies and many others (Katalinic, 2010). One very common approach for computer literacy is based on the idea that workers have some basic need for familiarity with computers in order to compete at the job 
Pardanjac, M.; Jokic, S.; Stanisavljev, S.; Zubanov, V.; Tasic, I. \& Milanov, D.: Pre...

market, or to be informed citizens. Computer literacy implies knowledge of how the computer does its work (calculate, compare and copy), but does not deal with how the computer works (digital circuits). It refers to ability to work with the operating system (Windows, Mac, Linux...), common applications such as word processors, spread sheets, database programs, e-mail programs and Web browsers. It also requires a basic understanding of systems design, application programming and datacenter operations. Also, the knowledge of working with information technologies is necessary (Kremljak \& Hocevar, 2014).

From presented conceptual opinions about computer literacy, it can be seen that it is a key competence required for E-training, and as such is incorporated into the starting point of E-training concept. In this context, computer literacy becomes a strategically important activity for E-training.

\section{Method}

\subsection{Aims and hypothesis of research}

The research aims to investigate current and potential role of the E-training in SME of the textile industry in Serbia. Given that education and competency of employees is an important factor that directly affects the effectiveness and efficiency of organization, training of employees should be one of the primary goals. The aim of this research is to examine all the different factors that positively and/or negatively affect the training of employees, as well as determining to which extent E-training can be used in that matter. The significance of this research reflects in the results that show the current state in examined organizations and gives suggestions on how managers can preventively work to increase positive and decrease negative factors. Thereby, the training of employees will be more efficient, they will possess more knowledge and skills, which will directly contribute to increasing the quality of work performed, and thus affect the efficiency and effectiveness of the organization.

Based on that, hypothesis can be that the implementation of E-training in SME in the textile industry can affect the increase of the level of expertise and competency of employees, tertian literacy, enabling new skills and knowledge, motivation, and all in the aim to increase the productivity and competency.

\subsection{Sample and organization of the research}

The research, which this paper included, has both empirical and theoretical character. The sample is a representative focus group consisting of employees from 32 SME textile organizations from Serbia, 23 - 65 years of age, surveyed during period from year 2012 to 2014 .

It well describes the workers structure by gender, age, years of service and education level. For the sample to be in the $95 \%$ level of confidence and the interval of confidence $\pm 5 \%$, targeted sample should be 366 participants. The sample size achieved in this study is 375 participants (114 men and 261 women) (Table 1.). Pearson correlation was used and statistically significant correlations were marked as: ${ }^{*} \mathrm{p}<0.05$; $* * \mathrm{p}<0.01$. 


\begin{tabular}{|l|c|c|c|c|}
\hline Dimensions & Min. & Max. & Mean & Std. Dev. \\
\hline Gender & 1 & 2 & 1.70 & 0.46 \\
\hline Age & 1 & 3 & 2.21 & 0.72 \\
\hline Education level & 1 & 3 & 1.14 & 0.43 \\
\hline
\end{tabular}

Tab. 1. Descriptive statistics

\begin{tabular}{|l|c|c|c|c|c|}
\hline \multirow{2}{*}{ Statement } & \multicolumn{5}{|c|}{ Descriptive statistics } \\
\cline { 2 - 6 } & $\begin{array}{l}\text { Short } \\
\text { name }\end{array}$ & Min & Max & Mean & St. D. \\
\hline I have technology necessary for e-training & ST1 & 1 & 2 & 1.67 & 0.47 \\
\hline $\begin{array}{l}\text { I have ability to download and install the } \\
\text { software }\end{array}$ & ST2 & 1 & 5 & 3.80 & 1.28 \\
\hline $\begin{array}{l}\text { I understand basic operations related to working } \\
\text { with files: creation, renaming... }\end{array}$ & ST3 & 1 & 5 & 4.20 & 0.83 \\
\hline $\begin{array}{l}\text { I am capable to communicate via e-mail, } \\
\text { forums and chat rooms }\end{array}$ & ST4 & 1 & 5 & 3.20 & 1.42 \\
\hline I always persist in achieving my goals & ST5 & 1 & 2 & 2.82 & 1.09 \\
\hline $\begin{array}{l}\text { I am organized, motivated and self-disciplined } \\
\text { worker }\end{array}$ & ST6 & 1 & 5 & 3.80 & 1.33 \\
\hline I think it makes no sense to plan a lot ahead & ST7 & 1 & 5 & 2.81 & 1.10 \\
\hline $\begin{array}{l}\text { One should have a clearly defined goal at any } \\
\text { time }\end{array}$ & ST8 & 1 & 5 & 2.79 & 1.07 \\
\hline It is important for me to point out my success. & ST9 & 1 & 5 & 2.93 & 1.10 \\
\hline $\begin{array}{l}\text { I have valuable experience in learning from e- } \\
\text { training courses. }\end{array}$ & ET1 & 1 & 3 & 2.20 & 0.83 \\
\hline Course materials are appropriate and concise. & ET2 & 1 & 3 & 2.13 & 0.81 \\
\hline The examples and tasks are relevant and useful. & ET3 & 1 & 3 & 2.20 & 0.83 \\
\hline $\begin{array}{l}\text { Workload is appropriate to the length of ET } \\
\text { class time. }\end{array}$ & ET4 & 1 & 3 & 2.07 & 0.77 \\
\hline $\begin{array}{l}\text { The instructors encouraged me to become } \\
\text { actively involved in the courses discussions. }\end{array}$ & ET5 & 1 & 3 & 2.13 & 0.81 \\
\hline $\begin{array}{l}\text { The instructors provided me feedback on my } \\
\text { work through comments. }\end{array}$ & ET6 & 1 & 3 & 2.13 & 0.81 \\
\hline $\begin{array}{l}\text { I was able to interact with the instructors during } \\
\text { the courses discussions. }\end{array}$ & ET7 & 1 & 3 & 2.20 & 0.83 \\
\hline The instructors treated me individually & ET8 & 1 & 3 & 2.19 & 0.83 \\
\hline $\begin{array}{l}\text { The instructors informed me about my progress } \\
\text { periodically. }\end{array}$ & ET9 & 1 & 3 & 2.19 & 0.77 \\
\hline Tab. 2. Descrptive statistics/statments & & 1 & & & \\
\hline
\end{tabular}

Tab. 2. Descriptive statistics/statements

The research part uses the survey method through questionnaires, which were developed specially for the purpose of this manuscript. For the age structure and educational level, questionnaires with offered answers were used. The questionnaire used in this study for computer literacy, motivation and opinion about E-training had 
Pardanjac, M.; Jokic, S.; Stanisavljev, S.; Zubanov, V.; Tasic, I. \& Milanov, D.: Pre...

3 sets of questions (Table 2). The first set of questions is linked to the level of computer literacy and second to the motivation of workers. The third set of questions is linked to the opinion about E-training. Some questions are with alternative answers, while some answers express attitudes. In that case the respondent gives answers by the level of his agreement or disagreement with the content of the statements. The values are as follows: $\mathrm{A}=\mathrm{I}$ absolutely agree, $\mathrm{B}=\mathrm{I}$ agree, $\mathrm{C}=$ No opinion, $\mathrm{D}=\mathrm{I}$ disagree, $\mathrm{E}=\mathrm{I}$ absolutely disagree.

\section{Findings}

\subsection{Age structure of employees}

By the age structure, the distribution of respondents is as follows (Figure 1.): from 2035 years (I), from $36-50$ years (II), from 51 years (III).

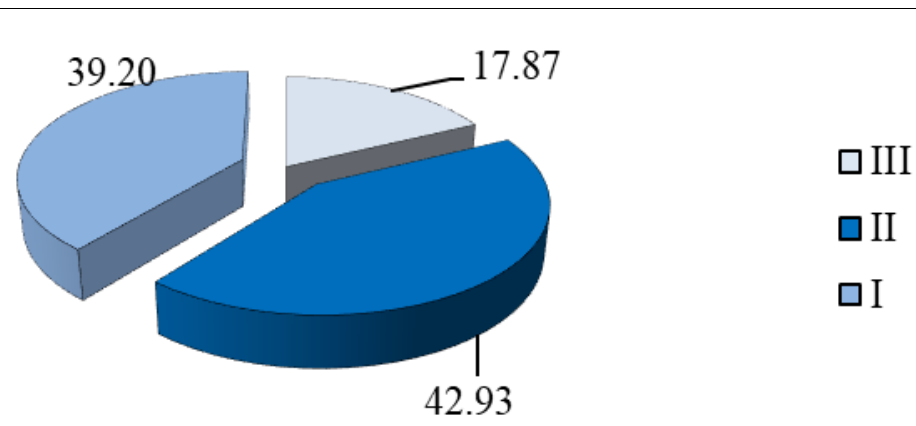

Fig. 1. Distribution of participant by age structure

To better understanding of how the age structure influence on the E-training, correlate analysis has been established between these important factors of SME in the textile industry (Figure 2.).

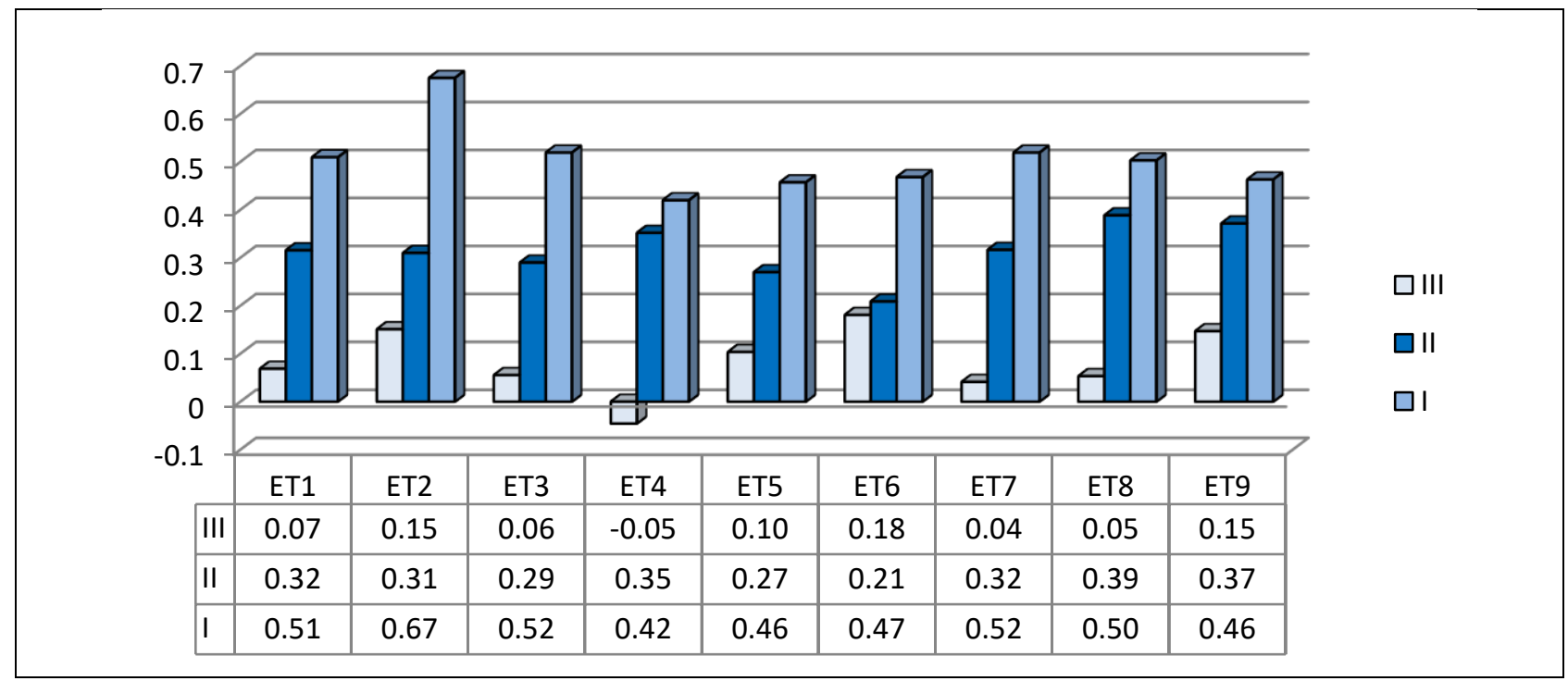

Fig. 2. Correlation between respondents' age and their opinion about E-training 


\subsection{Educational structure of employees}

By education level - professional qualifications level, distribution of participants was as follows (Figure 3.): faculty (I), college (II), elementary/secondary school (III).

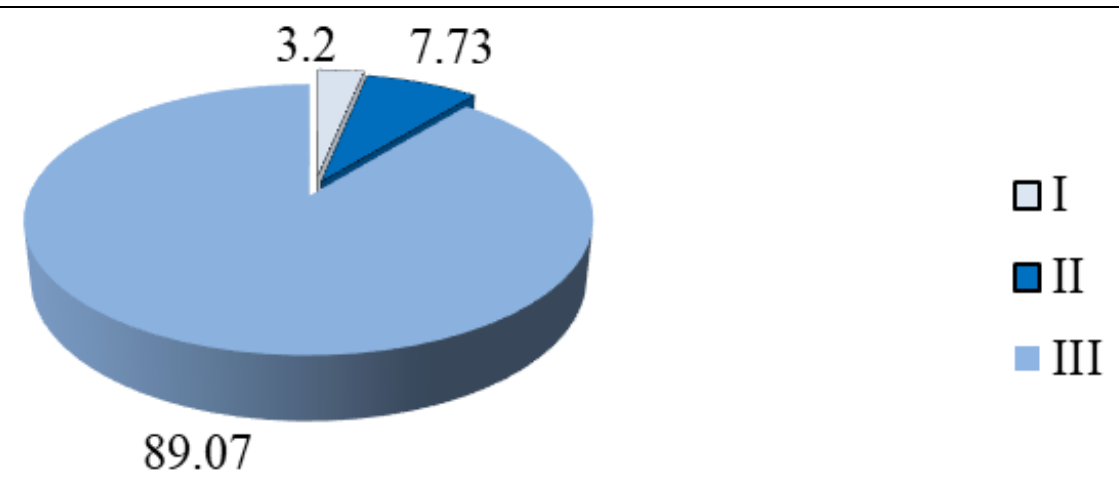

Fig. 3. Distribution of participant by total years of service

As seen, in SME in the textile industry in Serbia the low qualified work force is dominant. The influence that this fact has on E-training can be seen from the results of the correlation analysis (Figure 4.).

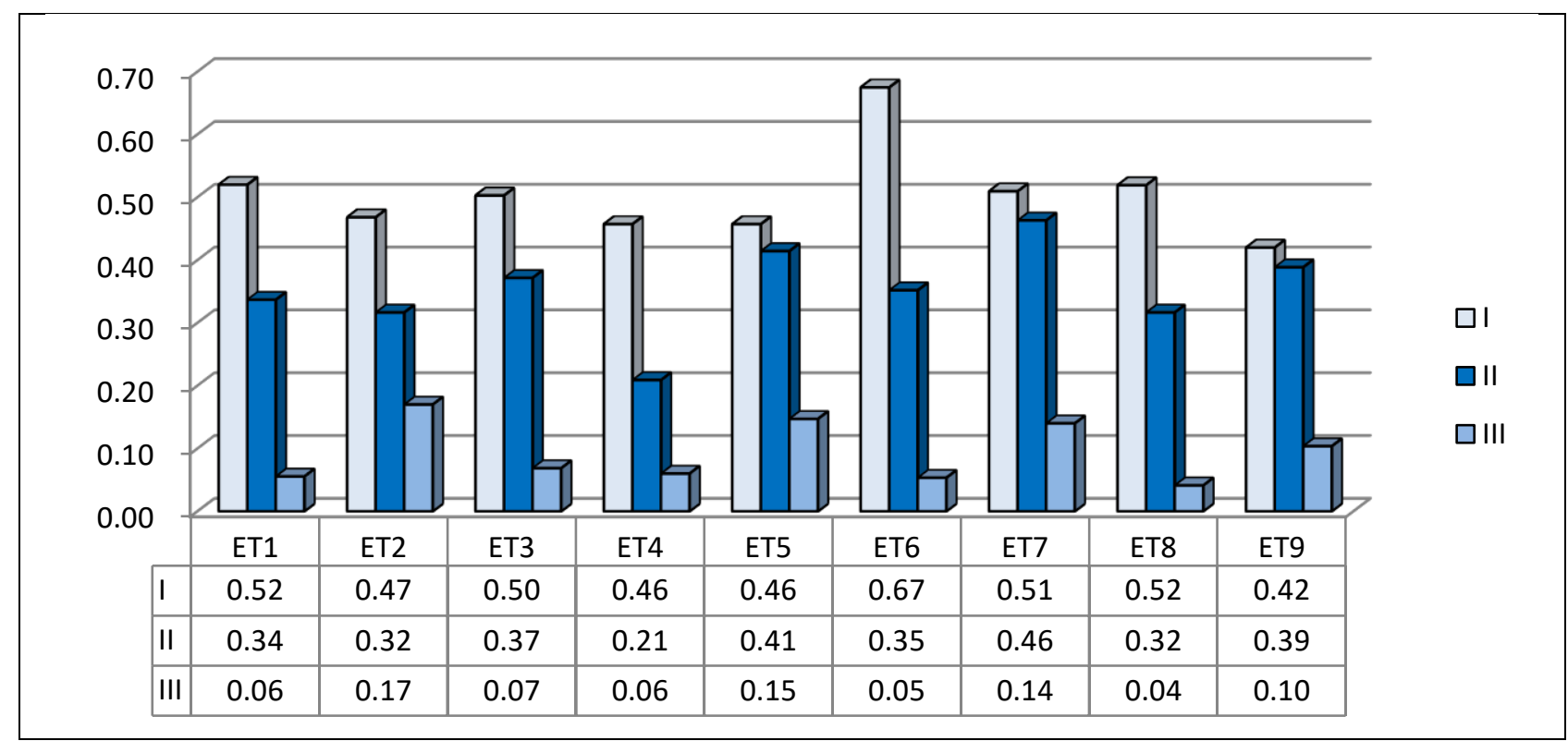

Fig. 4. Correlation between respondents' education level and their opinion about etraining

\subsection{Computer literacy and motivation}

\begin{tabular}{|l|l|l|l|l|l|l|l|l|l|}
\hline & ET1 & ET2 & ET3 & ET4 & ET5 & ET6 & ET7 & ET8 & ET9 \\
\hline ST1 & $0,51^{* *}$ & $0,64^{* *}$ & $0,51^{* *}$ & $0,43^{* *}$ & $0,47^{* *}$ & $0,47^{* *}$ & $0,51^{* *}$ & $0,50^{* *}$ & $0,47^{* *}$ \\
\hline ST2 & $0,41^{* *}$ & $0,67^{* *}$ & $0,41^{* *}$ & $0,42^{* *}$ & $0,35^{* *}$ & $0,42^{* *}$ & $0,41^{* *}$ & $0,41^{* *}$ & $0,42^{* *}$ \\
\hline ST3 & $0,52^{* *}$ & $0,46^{* *}$ & $0,52^{* *}$ & $0,39^{* *}$ & $0,46^{* *}$ & $0,46^{* *}$ & $0,52^{* *}$ & $0,51^{* *}$ & $0,46^{* *}$ \\
\hline ST4 & $0,47^{* *}$ & $0,15^{* *}$ & $0,47^{* *}$ & $0,35^{* *}$ & $0,38^{* *}$ & $0,50^{* *}$ & $0,47^{* *}$ & $0,47^{* *}$ & $0,50^{* *}$ \\
\hline ST5 & 0,07 & $0,36^{* *}$ & 0,07 & $-0,03$ & $0,13^{* *}$ & $0,21^{* *}$ & 0,07 & 0,07 & $0,21^{* *}$ \\
\hline
\end{tabular}


Pardanjac, M.; Jokic, S.; Stanisavljev, S.; Zubanov, V.; Tasic, I. \& Milanov, D.: Pre...

\begin{tabular}{|l|l|l|l|l|l|l|l|l|l|}
\hline ST6 & $0,40^{* *}$ & $0,40^{* *}$ & $0,40^{* *}$ & $0,27^{* *}$ & $0,34^{* *}$ & $0,52^{* *}$ & $0,40^{* *}$ & $0,39^{* *}$ & $0,52^{* *}$ \\
\hline ST7 & 0,06 & $0,34^{* *}$ & 0,06 & $-0,05$ & $0,11^{*}$ & $0,20^{* *}$ & 0,06 & 0,05 & $0,20^{* *}$ \\
\hline ST8 & 0,04 & $0,34^{* *}$ & $0,04^{* *}$ & $-0,06$ & $0,10^{*}$ & $0,18^{* *}$ & 0,04 & 0,04 & $0,18^{* *}$ \\
\hline ST9 & $0,32^{* *}$ & $0,32^{* *}$ & $0,32^{* *}$ & $0,17^{* *}$ & $0,40^{* *}$ & $0,40^{* *}$ & $0,32^{* *}$ & $0,29^{* *}$ & $0,40^{* *}$ \\
\hline
\end{tabular}

Tab. 3 Descriptive statistics / statements

The next factors that affect organizing E-training are computer literacy and motivation of employees for that type of training. To analyze its affect, Pearson's correlation coefficient was applied and the results are seen in Table 3.

\section{Discussion and conclusion}

Employees in late work years (Figure 1, marked with III) are less motivated for the work and performance. Because of that, their willingness for additional education is much less expressed than with younger employees, especially, when it comes to training using IT technologies.

Based on the results of correlate analysis (Figure 2.) it can be determined that the older employees are less interested in education through E-training. Older employees, even though they have computer equipment and technology, are not much interested in working with it. As potential cause for that is fear of the unknown, insufficient computer foreknowledge, the lack of interest in additional training in late ages, etc. The fact is that younger employees use IT technology themselves, therefore they need less time, and they can become familiar with new computer-guided machines quicker and easier. Therefore, younger structure of employees is more beneficial than older. On the other hand, since almost $89 \%$ of employees are individuals with elementary or high school degree, the level of their interest in additional training is very low. They do not have a high enough level of awareness of E-training advantages, therefore mangers of SME needs to invest additional effort to present E-training to them. On that way, not only the employees would benefit from it, but also the enterprises itself in terms of better management and better positioning on the market. Employees that are in younger age, as well as employees with higher education level, recognize all benefits of this type of training.

Almost all SME in the textile industry conducts trainings and educations of employees. Training is mostly technical (working on a new machine or training for a new work type). Although there is a high awareness on necessity and advantages of trainings, they are rarely conducted through E-training. Positive attitudes towards Etrainings and trainings in general, are characteristic within employees with high levels of education (I). They have a high level of awareness for importance of permanent education and training for personal and career development, and all with aim to increase their level of competency and skills to achieve tasks and business goals in more efficient way. In majority of SME, managers find E-training beneficial for employee motivation and competency increase, because it provides indirect increase of the business efficiency, and better market positioning. Because of that, it is necessary for managers in SME in the textile industry to ensure that workforce is consisted from younger employees who do not have an issue with additional E-training. 
The results that show strong correlation between having computer literacy and interest in E-training, brings conclusion that the computer literacy is fundamental for that type of training. Employees, who have computer literacy, have distinctive positive attitudes towards E-training, unlike ones who don't have. Therefore, it is necessary to increase computer literacy among all employees to a certain level, in order to engage them successfully through that type of training.

The belief that the content foreseen for E-training is overwhelming causes employees to give up easily from their set goals - negative correlation between ST5 and ET4. For that reason, they consider that there is no purpose for planning and setting goals in advance or they constantly change them and give up on initial set goals negative weak correlation between ST7, ST8 and ET4. Other fundamental factor for E-training is motivation, but the results determine that between them there is mostly positive, although weak correlation.

Faster pace of technology process development imposes a need for constant education of employees, their constant additional training and mastering of new technologies. Without constant improvement, there is no prosperity of the individual inside an enterprise or prosperity of a business in its sector. Investment in work force (physical and mental development) seen from financial point, increases profit more than direct investment in the production expansion. Based on that, it is clear that investment in education and training of staff affects productivity.

The fact is that the employer has to invest certain capital into the process of additional qualification or requalification, for an average qualified employee to become high qualified employee, or for existing employees to be trained for work with new, more modern machines. With the industry development, those costs increase. In Serbia, investment in human capital has always been on a low level. Starting costs for training of staff often seemed expensive compared to possible benefits of it. Level of investment in sending employees on seminars or summits that relate to newest findings from certain area is especially low. Staff training also affects the development of teamwork, facilitates them the ability to interact - collaborate efficiently, which affects the achievement of broader business goals and improve their own performance (Kremljak \& Hocevar, 2014).

The fact is that the employer has to invest certain capital into the process of additional qualification or requalification, for an average qualified employee to become high qualified employee, or for existing employees to be trained for work with new, more modern machines. With the industry development, those costs increase. In Serbia, investment in human capital has always been on a low level. Starting costs for training of staff often seemed expensive compared to possible benefits of it. Level of investment in sending employees on seminars or trainings that relate to newest findings from certain area is especially low. Staff training also affects the development of teamwork, facilitates them the ability to interact - collaborate efficiently, which affects the achievement of broader business goals and improve their own performance (Kremljak \& Hocevar, 2014).

The textile industry in Serbia is often faced with incompetence of employees in adequate skills and knowledge for: completing tasks related to workplace, long time needed for the task introduction, unwillingness for teamwork, insufficient 
Pardanjac, M.; Jokic, S.; Stanisavljev, S.; Zubanov, V.; Tasic, I. \& Milanov, D.: Pre...

communicational and problem solving skills, gap between theoretical and practical knowledge and skills, lack of knowledge on new technologies, quality systems, etc. (Poznanović \& Lazić, 2015).

The biggest remarks of foreign experts, except to deficiency and obsolescence of equipment, regard on bad organization of production itself and the lack of expert teams, the experience and expertise of the workforce. Remarks are also made on the slow reaction on customer demands and the lack of a defined market (production for certain customer groups). Opposite to that, flexibility of the workforce, readiness to learn, improve and ability to adapt quickly to new system is emphasized.

Competence development in the context of internationalization and globalization is not a general goal for itself or a universal task of all small and medium-sized enterprises. Some SMEs - especially those that are completely oriented to the domestic market - are not directly affected by globalization. For this reason, additional e-training of employees is not necessary, but is recommended for the benefits that it brings.

E-training for improving the capacity of SMEs at global and transnational market should be developed and designed strictly orientated towards the needs, objectives and expected results of the specific job. SME management should focus on predicting changes that may arise after the training of the staff via e-training - this primarily refers to the process of adaptation to internationalization and dealing with the challenges of globalization.

The necessity for adaptation to modern business trends leads to a clear need for e-training, all in conjunction with the company's strategy. Improving the quality and performance (for example, greater versatility of employee's skills) will allow SME to have a comparative advantage even if costs slightly increase.

Implementing new forms of learning that are well adapted to the organizational constraints of SMEs: E-training, distance learning, as well as the implementation of non-conventional forms of learning through international mobility or even the reception of foreigners will contribute to the internationalization of the companies and increase the skills and abilities of employees, and thus indirectly impact on the business results.

All previously exposed, confirms hypothesis that introduction of E-training in SME in the textile industry can raise the level of expertise and competency of employees, also a level of computer literacy, enable new skills and knowledge, motivation - all in the aim to increase productiveness and competency. From that follows that E-training has its advantages that positively affect whole development and prosperity of SME in the textile industry. The authors found that the results of research conducted in this paper, are comparable to similar experiences of international practice (Palcic, Koren \& Buchmeister, 2014; Zaniboni, Truxillo \& Fraccaroli, 2013; Bianchi, Bottacin \& Simonella, 2001, Lehmann \& Benner, 2015). A numerous support measures for SMEs of textile branch, that Serbian government has offered in the past few years, speaks a lot about the importance of E-training for this sector. The aim of that support is to empower SME of Serbian textile industry to set and achieve goals to better offer their products to customers, as well as to develop long term partner relationships with other mutual companies and on that way secure the productivity and efficiency. 


\section{Acknowledgement}

Serbian Ministry of Education, Science and Technological Development: Project No. TR 35017.

\section{References}

Bachman, K. (2010). Corporate E-Learning: Exploring A New Frontier, Available from: http://www.internettime.com/Learning/articles/hambrecht.pdf Accessed: 2016$10-15$

Bianchi, A.; Bottacin, P. \& Simonella, I. (2001). Electronic commerce business impacts project textile-clothing sector in Italy, Available from: http://www.oecd.org/sti/ieconomy/2675551.pdf Accessed: 2016-11-17

Blundell, R.; Dearden, L.; Meghir C. \& Sianesi, B. (1999) Human Capital Investment: The Returns from Education and Training to the Individual, the Firm and the Economy. Fiscal Studies, Vol. 20, No. 1, pp. 1-23, ISSN 1475-5890

Derouin, R. E.; Fritzsche, B. A. \& Salas, E. (2005). E-Learning in Organizations. Journal of Management, Vol. 31, No. 6, pp. 920-940, ISSN 0149-2063

Evans, C. \& Fan, P. F. (2002) Lifelong learning through the virtual university. CampusWide Information Systems, Vol. 19, No. 4, pp. 127-134, ISSN 1065-0741

Fisher, E. A. (2009). Motivation and Leadership in Social Work Management: A Review of Theories and Related Studies. Administration in Social Work, Vol. 33, No. 4, pp. 347-367, ISSN 0364-3107

Hamburg, I. (2005), Lifelong Learning, E-Learning and Business Development in Small and Medium Enterprises, Proceedings of EDEN 2005 Annual Conference, Szucs, A. \& Bo, I. (Ed.), pp. 79-84, ISBN 963-218-134-4, Helsinki, Jun 2005, EDEN, Budapest

Jokic, S.; Pardanjac, M. \& Bradonjic, D. (2010). Business and e-learning, Proceedings of SISY, Takacs, M. (Ed.), pp. 591-595, ISBN 9781424473946, Subotica, September 2010, IEEE, Subotica

Jovanovic, R. (2005). Tekstilna industrija Srbije, G17 Institut, Beograd

Katalinic, B. (2010). Engineers For Knowledge Based Society, Annals of DAAAM for 2010 \& Proceedings of the 21 st International DAAAM Symposium, Katalinic, B. (Ed.), pp. 1-2, ISBN 978-3-901509-73-5, Zadar, October 2010, DAAAM International, Vienna

Kennedy, H. QC. (1997). Learning Works Widening Participation in Further Education, FEFC, Coventry, England

Kooij, D. T. A. M.; De Lange, A. H.; Jansen, P. G. W.; Kanfer, R. \& Dikkers, J. S. E. (2011). Age and work-related motives: Results of a meta-analysis. Journal of Organizational Behavior, Vol. 32, No. 2, pp. 197-225, ISSN 1099-1379

Kremljak, Z. \& Hocevar, M. (2014). Restructuring a Production Company Into a Production Logistics Centre, In: DAAAM International Scientific Book 2014, Katalinic, B. (Ed.), pp.071-086, DAAAM International, ISBN 978-3-901509-98-8, Vienna Lehmann, T. \& Benner, M., (2015). Cluster Policy in the Light of Institutional ContextA Comparative Study of Transition Countries. Administrative Sciences, Vol. 5, No. 4, 
Pardanjac, M.; Jokic, S.; Stanisavljev, S.; Zubanov, V.; Tasic, I. \& Milanov, D.: Pre...

pp. 188-212; ISSN 2076-3387

McNaughton M. (2001) Distance learning: one student's perspective. Academic Exchange Quarterly, Vol. 5, No. 4, pp. 174-179, ISSN 1096-1453

Ng, T. W. H. \& Feldman, D. C., (2008). The relationship of age to ten dimensions of job performance. Journal of Applied Psychology, Vol. 93, No. 2, pp. 392-423. ISSN 0021-9010

Ng, T. W. H. \& Feldman, D. C. (2013). How do within-person changes due to aging affect job performance? Journal of Vocational Behavior, Vol. 83, No. 3, pp. 500-513, ISSN: 0001-8791

Palcic, I.; Koren, R. \& Buchmeister, B. (2014). Technical and Organizational Innovation in Slovenian Manufacturing Companies, In: DAAAM International Scientific Book 2014, Katalinic, B. (Ed.), pp.019-032, DAAAM International, ISBN 978-3-901509-98-8, Vienna

Poznanovic, S. \& Lazic, B. (2015). Improving the textile industry in Serbia through employee education, Proceedings of the SYNTHESIS, Stanisic, M. (Ed.), pp. 297-302, ISBN 978-86-7912-595-8, Belgrade, April 2015, Singidunum University, Belgrade Raymond, F. B. (2000). Delivering distance education through technology: a pioneers experience. Campus-Wide Information Systems, Vol. 17, No. 2, pp. 49-55, ISSN 1065 0741

Roberts, G. C.; Treasure, D. C. \& Conroy, D. E. (2007). Understanding the Dynamics of Motivation in Sport and Physical Activity, In: Handbook of Sport Psychology, Tenenbaum, G. \& Eklund, R. C. (Ed.), pp. 3-31, WILEY, ISBN: 978-0-471-73811-4, New Jersey

Tight, M. (2002), Key Concepts in Adult Education and Training, Routledge/Falmer, ISBN 0415275792, New York

Tynjala, P. \& Hakkinen, P. (2010). E-Learning at Work: Theoretical Underpinnings and Pedagogical Challenges. Journal of Workplace Learning, Vol. 17, No. 5/6, pp. 318-336, ISSN 1366-5626

Van der Heijden, B. I. J. M. (2006). Age differences in career activities among higherlevel employees in the Netherlands: A comparison between profit sector and non-profit sector staff. International Journal of Training and Development, Vol. 10, No. 2, pp. 98-120. ISSN 1468-2419

Van der Heijden, B. I. J. M.; De Lange, A. H.; Demerouti, E. \& Van der Heijde, C. M. (2009). Age as moderator in the relationship between self- versus supervisor ratings of employability and career success. Journal of Vocational Behavior, Vol. 74, No. 2, pp. 156-164, ISSN: 0001-8791

Wang, M.; Zhan, Y.; Liu, S. \& Shultz, K. S. (2008). Antecedents of bridge employment: A longitudinal investigation. Journal of Applied Psychology, Vol. 93, No. 4, pp. 818-830, ISSN 0021-9010

Zaniboni, S.; Truxillo, D. M. \& Fraccaroli, F. (2013). Differential effects of task variety and skill variety on burnout and turnover intentions for older and younger workers, European Journal of Work and Organizational Psychology, Vol. 22, No. 3, pp. 306317, ISSN 1359-432X 